\title{
Psychometric properties of the Chinese version of the spiritual care-giving scale (C- SCGS) in nursing practice
}

Yanli Hu', Lay Hwa Tiew ${ }^{2}$ and Fan $\mathrm{Li}^{1,3,4,5^{*}}$

\begin{abstract}
Background: Spiritual care is defined as recognizing and responding to the needs of the human spirit when the individual is facing trauma, illness, or sadness. Providing spiritual care is one of the core aspects of holistic care, as it is significantly associated with patients' quality of life. The provision of optimal spiritual care requires good understanding by the nurses. Therefore, it is important to assess this understanding by using a proven, well-validated instrument. The Spiritual Care-Giving Scale (SCGS) is designed to measure nurses' perceptions of spirituality and spiritual care in Singapore. However, it is unknown whether this scale is valid and reliable for use with nurses in the context of Chinese culture. The purpose of this study is to determine this version's validity and reliability for use with nurses in China.

Methods: In this quantitative, descriptive, cross-sectional study, after translating the English version of the SCGS into Chinese and making adjustments for culture and values, we assessed the performance of this instrument by administering the C-SCGS to a convenience sample of 400 nurses. The participants also completed the Chinese version of the Spiritual Care Competency Scale (C-SCCS) to assess the concurrent validity of the CSCGS. The internal consistency and homogeneity of the C-SCGS were also tested, and a factorial analysis was performed.
\end{abstract}

Results: Completed questionnaires were obtained from 355 participants (response rate: 88.75\%). Four factors were confirmed by an exploratory factor analysis (EFA) using Promax with the Kaiser normalization rotation method after

the 35 -item SCGS was reduced to 34 items, and these factors explained $53.116 \%$ of the total variance. The adjusted item-total correlation ranged from 0.527 to 0.760 . The Cronbach's alpha of the factors ranged from 0.836 to 0.941 ,

and the Guttman split-half coefficient was between 0.759 and 0.902 . The concurrent validity of the C-SCGS and C-SCCS $(r=0.534, p<0.01)$ showed a significant correlation. Nurses' education showed a significant association with the scores of the C-SCGS.

Conclusion: The C-SCGS was found to be a psychometrically sound measurement to evaluate Chinese-speaking nurses' perceptions of spirituality and spiritual care.

Keywords: Psychometrics, Spiritual care, Spirituality, Nurses

\footnotetext{
* Correspondence: lifan@jlu.edu.cn

${ }^{1}$ School of Nursing, Jilin University, Changchun, China

${ }^{3}$ Department of Pathogenobiology, The Key Laboratory of Zoonosis research,

Chinese Ministry of Education, College of Basic Medicine, Jilin University,

No.126 Xinmin Street, Changchun, China

Full list of author information is available at the end of the article
}

C The Author(s). 2019 Open Access This article is distributed under the terms of the Creative Commons Attribution 4.0 International License (http://creativecommons.org/licenses/by/4.0/), which permits unrestricted use, distribution, and reproduction in any medium, provided you give appropriate credit to the original author(s) and the source, provide a link to the Creative Commons license, and indicate if changes were made. The Creative Commons Public Domain Dedication waiver (http://creativecommons.org/publicdomain/zero/1.0/) applies to the data made available in this article, unless otherwise stated. 


\section{Background}

Spiritual well-being is an important component and predictor of patient health-related quality of life for individuals with chronic or severe diseases. Spiritual care is defined as recognizing and responding to the needs of the human spirit when the individual is facing trauma, illness, or sadness. It can include addressing the need for satisfactory meaning, self-worth, self-expression, the support of faith, the practice of rituals, prayers or sacraments, and conversation with sensitive listeners. Spiritual care is considered an essential part of palliative care and holistic care [1-7] because it can help enhance the physical, social, and psychological aspects of good health in patients by reducing tension and stress, increasing support and adaptation abilities, maintaining hope, and helping patients find meaning and purpose [1, 8-11]. Optimal spiritual care requires good understanding on the part of nurses [12-15] to allow them to discern what action is required with regard to the spiritual aspect of nursing practice and enable them to explore the resources available to improve patient care and enhance patient satisfaction [15-19]. A number of instruments have been developed to evaluate nurses' views on spirituality and spiritual care in several countries, such as the Spirituality and Spiritual Care Rating Scale (SSCRS) [20] and the Spiritual Care-Giving Scale (SCGS) [21]. However, such instruments are lacking in China. Although the C-SCCS was used for evaluation in this study, it is designed to measure the spiritual care capacity of clinical caregivers, and there is currently a lack of effective tools for assessing the spirituality and spiritual care perceptions of nurses. This issue needs to be addressed urgently to inform the education and training sector.

The Spiritual Care-Giving Scale (SCGS), a self-reported scale, was developed by Tiew [21]. Although the SCGS is primarily designed to measure nursing students' perspectives on spirituality or spiritual care, it has been used with nurses and is considered valid and reliable [22]. However, a critical question is whether this scale can be used with health providers from other cultural contexts, such as nurses in China. This study was designed to evaluate the psychometric properties of the SCGS in a Chinese-speaking nurse population and therefore had two main aims: 1) to translate the English version of the SCGS into Chinese and make cultural adjustments and 2) to evaluate the validity and reliability of the Chinese version (C-SCGS) for use with nurses from China. We hope our study will serve as a reference for the measurement, assessment and development of Chinese nurses' spiritual care knowledge, perception, and skill.

\section{Methods}

\section{Study design and participants}

Nurses were recruited from three university-affiliated comprehensive hospitals, two cancer centers, one psychiatric hospital, and two traditional Chinese medicine hospitals to complete this cross-sectional study. Nurses who were reluctant to participate in the study were excluded. A convenience sample of 400 nurses was recruited, which was adequate for exploratory factor analysis (EFA) according to the guideline of Monte Carlo study decision on sample size [23].

Data were collected between March and April 2018. This study was approved by the Institute Review Board of College of Nursing, Jilin University (access number: 2018031102).

\section{Instruments \\ The self-designed general condition questionnaire}

This form consisted of five questions about the participants' age, gender, education, length of work experience, and department, which demonstrated that the participants recruited are a representative sample of different backgrounds.

\section{The SCGS}

The SCGS is a 35-item self-reporting measure created by Tiew and Creedy [21]. The scale has significant test-retest reliability $(\mathrm{r}=0.811 ; p<0.01)$. It includes five core factors: attributes of spiritual care (Cronbach's alpha 0.926), spiritual perspectives (Cronbach's alpha 0.896), definitions of spiritual care (Cronbach's alpha 0.868), spiritual care attitudes (Cronbach's alpha 0.879), and spiritual care values (Cronbach's alpha 0.822). The SCGS revealed good psychometric properties.

\section{The Chinese version of the spiritual care competency scale (C-SCCS)}

The 27-item Spiritual Care Competency Scale (SCCS) developed by Leeuwen and colleagues [24] measures the competence of nurses in the provision of spiritual care to patients. The SCCS measures content in the same subject but in different dimensions and was therefore used to test the concurrent validity of the C-SCGS. The original SCCS consists of six factors with Cronbach's alpha values from 0.71 to 0.82 . The Chinese version, the C-SCCS, was translated and evaluated (using the same EFA method as for the translation and evaluation of the SCGS) by our study team with the permission of Dr. Leeuwen. It has three different components with good psychometric properties: the assessment, implementation, improvement, and professionalization of spiritual care (SCCS 1; Cronbach's alpha $=0.934$ ); personal and team support (SCCS 2: Cronbach's alpha $=0.917$ ); and attitude towards patient spirituality and communication (SCCS 3: Cronbach's alpha $=0.855$ ). The C-SCCS uses a five-point Likert rating response ranging from one (strongly disagree) to five (strongly agree). 


\section{Translation and adaptation procedures and psychometric testing}

The English version of the SCGS was translated into Chinese according to Brislin's translation model [25]. Permission to translate it was obtained from Dr. Tiew, the developer of the original SCGS. Phase I involved four steps. 1) Forward translation: two bilingual researchers interpreted the original SCGS into Chinese. After that, all members of the research team reviewed and discussed any incongruity in the two copies until consensus was reached. 2) Backtranslation: the translated version was then back-translated blindly into English by two experts not working in the nursing field. One studied and worked in an English-speaking country for 7 years; the other has been teaching English for many years in a university in China. Then, the two back-translation versions were compared, verified, and revised by Tiew himself, from which a final Chinese translation was obtained. 3) Evaluation of translation equivalence: the translation validity index (TVI) $[26,27]$ was used to assess the translation equivalence of the versions. A total of five experts were recruited to compare the original English version of the SCGS and the Chinese version. The TVI assessment form was a 4-point Likert scale $(1=$ not relevant, $2=$ needs major item modification to be equivalent, $3=$ equivalent but needs minor modification, and 4 =equivalent). Every item was revised until a translation equivalence score of 4 was achieved. 4) Evaluation of content validity: an expert panel was asked to evaluate each item on a four-point Likert scale (from irrelevant to absolutely relevant) to determine the content validity of each item and to confirm whether the items were designed properly to create the constructs. The expert panel included one specialist in oncology (age, 48 years; working years, 29 years; position, ICU charge nurse; title, vice-high-level), one nurse in an intensive care unit (age, 35 years; working years, 10 years; position, nurse; title, intermediate grade), two nursing professors (one: age, 48 years; working years, 19 years; position, associate dean; title, associate professor, Ph.D.; the other: age, 63 years; working years, 46 years; title, professor, Ph.D.), and one advanced-practice nurse specializing in palliative care (age, 32 years; working years, 10 years; position, head nurse; title, charge nurse). The items were evaluated individually. Ambiguous and/or complex terms were removed or rephrased until no changes to the Chinese translation were deemed necessary. We made some cultural adjustments to the expression of certain items according to the experts' advice after two rounds of consultation. Three items on religion were considered inappropriate by some experts. However, although only a small number of Chinese nurses have religious beliefs, the reciprocal relationship between nurses' religious beliefs and spiritual care seems obvious, and therefore, the three items were retained.

Phase II consisted of two steps. 1) The revised version of the SCGS was pilot tested to evaluate whether the C-SCGS was easy to understand and answer in three Jinlin University affiliated teaching hospitals with a convenience sample of 17 nurses. 2) The psychometric properties of the C-SCGS were evaluated, including item analysis, construct validity, concurrent validity, internal consistency reliability, and split-half reliability. The construct validity of the C-SCGS was determined by performing the principal axis factoring extraction method with Promax with Kaiser normalization rotation. The concurrent validity refers to the comparison of the results of a test using the targeted instrument with those of another effective test using another valid measuring method at the same time by adopting a quantitative method of calculating the correlation coefficient. In this study, the Pearson correlation coefficients of the C-SCGS and the Chinese version of the Spiritual Care Competency Scale (C-SCCS) were calculated to assess the concurrent validity of the C-SCGS. To verify the quality of the component structure, we conducted a confirmatory factor analysis (CFA) based on an additional data sample obtained from 351 nurses. (In this study, a total of 707 data points were collected and divided into two samples by a computerized random method using SPSS 17.0. One sample, including the information from 355 nurses, was used for EFA, and the other, including the information from 351 nurses, was used for CFA. Although a convenient sampling method was adopted for sample selection, stratification sampling was used as far as possible, taking into account the multiple departments of various types and levels of hospitals, to obtain a representative sample reflecting the topic of this study. See Table 1). We also tested the internal consistency and stability of the C-SCGS by using Cronbach's alpha coefficient and the Guttman split-half coefficient, respectively.

\section{Data collection}

A professional platform called SO JUMP was used for the data collection [28]. First, the content of the questionnaire was entered into a computer. Then, the questionnaire was sent to individual nurses through WeChat (a total of 17 nurses) and to $4 \mathrm{WeChat}$ chat groups with relatively fixed numbers of nurses (group 1, 52; group 2, 65; group 3, 60; and group 4,206) over WhatsApp (three of these chat groups were established as part of this research, and one has been used previously for the continuing education of a 
Table 1 Social and demographic information of the participants $(n=355)$

\begin{tabular}{|c|c|c|}
\hline Descriptive characteristics & Frequency (n) & Percentage (\%) \\
\hline \multicolumn{3}{|l|}{ Gender } \\
\hline Male & 17 & 4.8 \\
\hline Female & 338 & 95.2 \\
\hline \multicolumn{3}{|l|}{ Age, years } \\
\hline$\geq 18$ & 54 & 15.2 \\
\hline$\geq 26$ & 130 & 36.6 \\
\hline$\geq 31$ & 129 & 36.3 \\
\hline$\geq 41$ & 36 & 10.1 \\
\hline$\geq 51$ & 6 & 1.7 \\
\hline \multicolumn{3}{|l|}{ Marital status } \\
\hline Unmarried & 96 & 27.0 \\
\hline Married & 253 & 71.3 \\
\hline Divorced or widowed & 6 & 1.7 \\
\hline \multicolumn{3}{|l|}{ Education } \\
\hline $\begin{array}{l}\text { Secondary vocational } \\
\text { schools }\end{array}$ & 3 & .8 \\
\hline Junior college & 72 & 20.3 \\
\hline Undergraduate & 250 & 70.4 \\
\hline Postgraduate or above & 30 & 8.5 \\
\hline \multicolumn{3}{|l|}{ Income(¥/month) } \\
\hline$<5000$ & 193 & 54.4 \\
\hline$\geq 5000$ & 162 & 45.6 \\
\hline Working years $(\mathrm{M} \pm \mathrm{SD})$ & 10.3 & 8.7 \\
\hline \multicolumn{3}{|l|}{ Type of hospital } \\
\hline Comprehensive hospital & 150 & 42.3 \\
\hline Tumor hospital & 35 & 9.9 \\
\hline Psychiatric hospital & 48 & 13.5 \\
\hline $\begin{array}{l}\text { Traditional Chinese } \\
\text { medicine (TCM) hospital }\end{array}$ & 116 & 32.7 \\
\hline $\begin{array}{l}\text { Marital and child service } \\
\text { care center }\end{array}$ & 2 & 6 \\
\hline Others & 4 & 1.1 \\
\hline \multicolumn{3}{|l|}{ Department } \\
\hline Internal medicine & 126 & 35.5 \\
\hline Surgical & 53 & 14.9 \\
\hline Pediatric & 13 & 3.7 \\
\hline Obstetrics and gynecology & 43 & 12.1 \\
\hline Emergency & 11 & 3.1 \\
\hline ICU & 12 & 3.4 \\
\hline The operating room & 8 & 2.3 \\
\hline Outpatient service & 11 & 3.1 \\
\hline Psychiatric & 42 & 11.8 \\
\hline Others & 36 & 10.1 \\
\hline
\end{tabular}

Professional title
Table 1 Social and demographic information of the participants ( $n=355)$ (Continued)

\begin{tabular}{lll}
\hline Descriptive characteristics & Frequency $(\mathrm{n})$ & Percentage (\%) \\
\hline Primary nurse & 84 & 23.7 \\
Nurse practitioner & 148 & 41.7 \\
Nurse-in-charge & 112 & 31.5 \\
Deputy director nurse & 11 & 3.1 \\
\hline
\end{tabular}

nurse team). Before answering the questionnaires, all participants were asked to sign a written consent form.

\section{Statistical analysis}

Statistical analyses were performed using SPSS 17.0 for Windows. Categorical variables were expressed as frequencies and percentages. Continuous variables were presented as the mean \pm standard deviation (SD) if the distribution was normal. Every subscale's internal consistency and homogeneity was assessed by Cronbach's alpha. Concurrent validity was assessed by the Pearson correlation coefficient between SCGS and SCCS. Item analysis was performed using the following analyses: (a) item analysis, (b) corrected item-total correlation, (c) factor loading, (d) Cronbach's alpha if an item was deleted, (e) extreme group comparison, and (f) communities. Items that had a criterial value $(\mathrm{CR})<3.0$, a corrected item-total correlation $<0.30$, factor loading $<0.40$, community $<0.20$ and whose deletion caused an increase of 0.5 or more in the alpha coefficient for the overall scale were excluded.

An EFA was performed by exploring the main components in the correlation matrix of every item, with a Promax with Kaiser normalization rotation and the Kaiser criterion to test the construct validity of the SCGS if the correlation coefficient between the factors was greater than 0.3. Prior to performing EFA, Kaiser-Meyer-Olkin $(\mathrm{KMO})$ and Bartlett's sphericity test were used to test the sampling adequacy and the suitability of the data for factor analysis. The criterion for factor extraction was an eigenvalue $>1.0$ since these values could explain a higher percentage of the total variability and a factor loading of $>0.40$. If the results of the standard EFA were not consistent with the original theoretical model of the SCGS, an alternative methodological consideration was to perform separate EFA for each SCGS subscale to evaluate the subscale dimensionality $[29,30]$. To contrast differences in the mean values of a quantitative variable, Student's t-test (in a continuous scale of two independent populations) or the $\mathrm{F}$ test was used (in a continuous scale of three or more independent populations). A $p$ value $<0.05$ was accepted as statistically significant.

AMOS version 20.0 was used to perform the CFA to further evaluate the validity of the C-SCGS. 
Table 2 Results of the Exploratory factor analysis of 34-items ${ }^{\mathrm{a}}$ C-SCGS ( $\left.\mathrm{n}=355\right)$

\begin{tabular}{|c|c|c|c|c|c|c|c|c|c|c|}
\hline \multicolumn{5}{|c|}{ The structure matrix of the promax oblique rotation axis } & \multicolumn{5}{|c|}{ The pattern matrix of the promax oblique rotation axis } & \multirow[t]{2}{*}{$\mathrm{C}^{2}$} \\
\hline Items & Factor 1 & Factor 2 & Factor 3 & Factor 4 & Items & Factor 1 & Factor 2 & Factor 3 & Factor 4 & \\
\hline B28 & .820 & .423 & .475 & .629 & B28 & .873 & -.135 & -.125 & .145 & .425 \\
\hline B27 & .796 & .414 & .513 & .635 & B29 & .796 & .079 & -.063 & -.061 & .533 \\
\hline B23 & .772 & .512 & .537 & .638 & B27 & .787 & -.130 & -.040 & .153 & .597 \\
\hline B25 & .768 & .476 & .506 & .571 & B32 & .786 & .070 & .053 & -.150 & .571 \\
\hline B24 & .765 & .484 & .593 & .622 & B25 & .744 & .023 & .041 & -.022 & .482 \\
\hline B29 & .759 & .500 & .429 & .529 & B34 & .706 & -.143 & .089 & .043 & .374 \\
\hline B31 & .757 & .503 & .545 & .558 & B30 & .698 & .105 & -.119 & .074 & .530 \\
\hline B32 & .750 & .481 & .472 & .508 & B31 & .689 & .087 & .147 & -.103 & .592 \\
\hline B30 & .741 & .520 & .416 & .567 & B23 & .634 & .052 & .035 & .115 & .379 \\
\hline B35 & .725 & .398 & .537 & .626 & B24 & .621 & .027 & .170 & .027 & .558 \\
\hline B34 & .708 & .342 & .508 & .548 & B35 & .603 & -.097 & .060 & .192 & .527 \\
\hline B26 & .688 & .535 & .506 & .513 & B26 & .555 & .207 & .161 & -.126 & .551 \\
\hline B16 & .637 & .612 & .455 & .622 & B22 & .389 & .268 & -.174 & .252 & .495 \\
\hline B22 & .627 & .575 & .355 & .569 & B21 & .111 & .828 & -.071 & -.262 & .477 \\
\hline B21 & .371 & .720 & .146 & .234 & B20 & -.001 & .701 & -.108 & .051 & .449 \\
\hline B20 & .391 & .686 & .206 & .367 & B15 & -.149 & .643 & .118 & .101 & .515 \\
\hline B18 & .611 & .664 & .445 & .570 & B17 & -.003 & .617 & .014 & .034 & .411 \\
\hline B15 & .388 & .656 & .350 & .433 & B6 & -.169 & .485 & .112 & .252 & .521 \\
\hline B19 & .628 & .655 & .448 & .527 & B18 & .226 & .440 & .035 & .132 & .517 \\
\hline B17 & .403 & .640 & .282 & .387 & B19 & .325 & .434 & .077 & -.010 & .477 \\
\hline B6 & .381 & .569 & .375 & .477 & B16 & .266 & .312 & -.024 & .267 & .566 \\
\hline B3 & .569 & .370 & .760 & .624 & B1 & -.121 & .008 & .740 & -.032 & .480 \\
\hline B4 & .548 & .367 & .749 & .578 & B2 & .129 & -.103 & .731 & -.069 & .608 \\
\hline B2 & .477 & .227 & .723 & .480 & B4 & .087 & .033 & .654 & .038 & .606 \\
\hline B5 & .487 & .390 & .681 & .540 & B3 & .080 & .002 & .616 & .133 & .591 \\
\hline B1 & .327 & .211 & .643 & .399 & B5 & -.008 & .124 & .593 & .062 & .509 \\
\hline B8 & .627 & .458 & .547 & .764 & B8 & .135 & .008 & -.006 & .663 & .649 \\
\hline B12 & .588 & .393 & .577 & .734 & B12 & .094 & -.053 & .105 & .622 & .691 \\
\hline B11 & .608 & .414 & .522 & .717 & B11 & .183 & -.031 & .001 & .598 & .584 \\
\hline B10 & .576 & .517 & .619 & .714 & B13 & .162 & .181 & -.130 & .538 & .565 \\
\hline B7 & .558 & .274 & .639 & .672 & B9 & -.186 & .288 & .038 & .522 & .588 \\
\hline B14 & .581 & .351 & .536 & .672 & B14 & .202 & -.093 & .086 & .514 & .572 \\
\hline B13 & .587 & .527 & .420 & .668 & B10 & -.031 & .177 & .239 & .471 & .520 \\
\hline B9 & .398 & .483 & .400 & .572 & B7 & .135 & -.189 & .303 & .466 & .551 \\
\hline
\end{tabular}

KMO $=0.951$, Bartlett $(p \text { value })^{2}=7632.213, \mathrm{df}=561, p=0.000$; Extraction Method: Principal Axis Factoring; Rotation Method: Promax with Kaiser Normalization

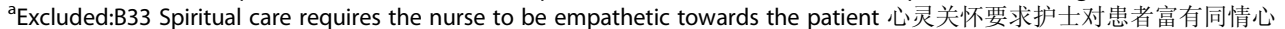

The Chinese version of the Spiritual Care-Giving Rating Scale (C-SCGS): Attributes for Spiritual Care (Factor 1), Defining Spirituality and Spiritual Care (Factor 2), Spirituality Perspectives (Factor 3), Spirituality and Spiritual Care Values (Factor 4). Item 16 entried in factor 2

\section{Results}

\section{Sample characteristics}

A total of 356 (out of a possible 400) nurses completed the survey, providing a response rate of $88.75 \%$. The majority of nurses were female $(n=338$, 95.2\%), married $(71.3 \%)$, and had completed undergraduate education (70.4\%). The average length of employment was 10.3 years. Sample characteristics are presented in Table 1.

\section{Psychometric analyses}

To assess face validity, the C-SCGS was given to 20 nurses (having more than 5 years of working experience; being familiar with the concepts of spirituality and 


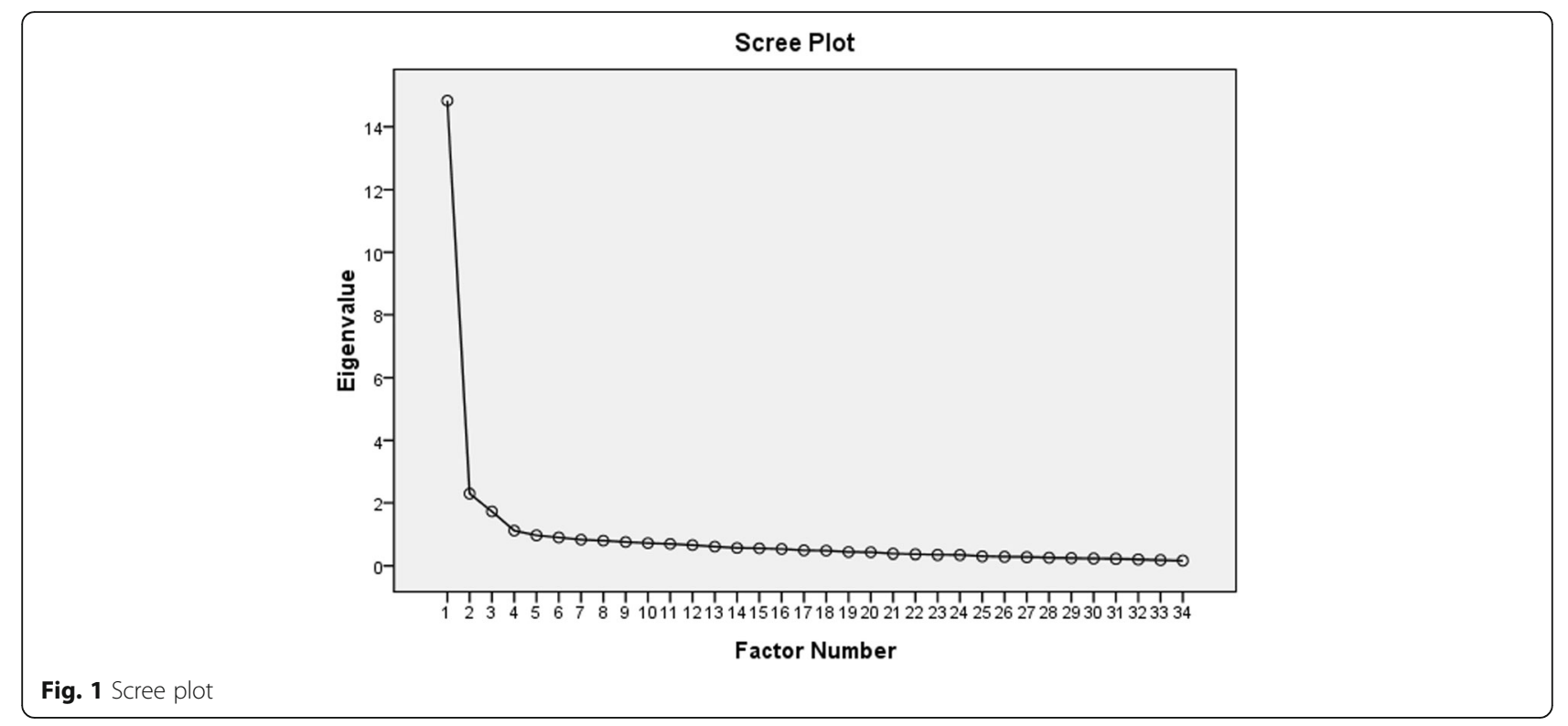

spiritual care; working in the ICU, oncology or palliative care unit) to understand how they perceived and interpreted the items by means of a purposive sampling strategy. The participants reported that the wording of the C-SCGS was clear and that they had little difficulty understanding it.

During the homogeneity analyses for each item, all 35 items of the SCGS were retained. Although the communality coefficient of item 1 (Q1) of the C-SCGS was lower than $0.20(0.172)$ and the corrected item-total correlation score was 0.390 (An additional table file shows this in more detail [see Additional file 1]), the results of expert consultation showed that four out of five experts believed the item had clinical significance. In addition, other indicators of this item meet the standards, so the experts recommended keeping this item. The internal consistency analysis of the 35-item C-SCGS showed that the Item-total correlations ranged from 0.427 to 0.829 ; CR values were all greater than 3.0; and all corrected item-total correlations ranged from 0.390 to 0.817 , indicating moderate to strong correlation (Table 2). No item deletion would have improved the Cronbach's alpha value of the scale.

To test the validity and reliability of the questionnaire, a factorial analysis was performed that showed the presence of an underlying structure composed of four factors (see Fig. 1. Scree plot), according to the Kaiser-Meyer-Olkin criteria. Bartlett's sphericity test was also performed. The correlation coefficients of the factors were all greater than 0.30 (Table 3). Therefore, this factor analysis was suitable for Promax with Kaiser normalization rotation. Item 33 was excluded because Factor 5 of the factorial analysis included only one item Q33 (An additional table file shows this in more detail [see Additional file 2]). The final questionnaire contained 34 items with a range of possible values between 134 and 210 points. The factors found in the factorial analysis accounted for $53.116 \%$ of the variance, and every factorial item had a value $>0.40$. The homogeneity tests for each of the four factors demonstrated a Cronbach's alpha value above 0.700 , and none of them were removed. After Promax with Kaiser normalization rotation, Factor 1 included thirteen items related to 'attributes of spiritual care' (items 22, 23, 24, 25, $26,27,28,29,30,31,32,34$, and 35), Factor 2 included eight items related to 'definitions of spirituality and spiritual care' (items 6, 15, 16, 17, 18, 19, 20, and 21), Factor 3 included five items related to 'spiritual perspectives' (items 1, 2, 3, 4, and 5), and Factor 4 contained eight items related to 'spirituality and spiritual care values' (items 7, 8, 9, $10,11,12,13$, and 14). The structure matrix showed that the factor loadings on Factor 1 (0.637) and Factor 2 (0.612) were similar, but the pattern matrix showed that item 16 was more important for Factor 2. Therefore, item 16 was included in Factor 2. (The items included in each of the four factors are shown in Table 4). For the four subscales of the C-SCGS, the corresponding Cronbach's alpha coefficients were $0.941,0.852,0.836$, and 0.866 ,

Table 3 The factor correlation matrix

\begin{tabular}{lllll}
\hline Factor Correlation Matrix & & & \\
\hline Factor & 1 & 2 & 3 & 4 \\
\hline 1 & 1.000 & .603 & .632 & .741 \\
2 & .603 & 1.000 & .399 & .560 \\
3 & .632 & .399 & 1.000 & .699 \\
4 & .741 & .560 & .699 & 1.000 \\
\hline
\end{tabular}

Extraction Method: Principal Axis Factoring

Rotation Method: Promax with Kaiser Normalization. 
Table 4 The results of factor analysis of the 34-item Spiritual Care-Giving Chinese version (C-SCGS) ( $n=355)$

\begin{tabular}{|c|c|c|c|c|}
\hline Items & $\begin{array}{l}\text { Corrected item-factor } \\
\text { correlation }\end{array}$ & $\begin{array}{l}\text { Cronbach's a if } \\
\text { item deleted }\end{array}$ & $\begin{array}{l}\text { Average } \\
\text { Mean }\end{array}$ & SD \\
\hline $\begin{array}{l}\text { Factor } 1^{\mathrm{b}} \text { Attributes for Spiritual Care } \\
\text { 维度1:灵性照护特点 (Cronbach's a = 0.941; Guttman Split-Half coefficient=0.902) }\end{array}$ & & & 5.01 & 0.49 \\
\hline $\begin{array}{l}\text { B22 I am comfortable providing spiritual care to patients. } \\
\text { 我舒心地为患者提供心灵关怀 }\end{array}$ & .605 & .941 & 4.87 & .821 \\
\hline $\begin{array}{l}\text { B23 Nurses provide spiritual care by respecting the dignity of patients. } \\
\text { 护士通过尊重患者的尊严为其提供心灵关怀 }\end{array}$ & .760 & .935 & 5.03 & .694 \\
\hline $\begin{array}{l}\text { B24 Spiritual care should take into account of what patients think about } \\
\text { spirituality } \\
\text { 心灵关怀应考虑到患者的心灵理念 }\end{array}$ & .750 & .935 & 5.03 & .621 \\
\hline $\begin{array}{l}\text { B25 Nurses who are spiritual aware are more likely to provide spiritual care. } \\
\text { 具有心灵意识的护士更有可能提供心灵照护 }\end{array}$ & .748 & .935 & 5.04 & .678 \\
\hline $\begin{array}{l}\text { B26 Spiritual care requires awareness of one's spirituality } \\
\text { 心灵关怀需意识到自身的心灵世界 }\end{array}$ & .666 & .938 & 5.00 & .703 \\
\hline $\begin{array}{l}\text { B27 Spiritual care should be instilled throughout a nursing education } \\
\text { programme } \\
\text { 心灵关怀的理念应融入护理教育课程 }\end{array}$ & .760 & .935 & 5.05 & .700 \\
\hline $\begin{array}{l}\text { B28 Spiritual care should be positively reinforced in nursing practice. } \\
\text { 心灵关怀应在护理实践中得到该积极加强 }\end{array}$ & .782 & .934 & 5.08 & .698 \\
\hline $\begin{array}{l}\text { B29 The ability to provide spiritual care develops through experience. } \\
\text { 提供心灵关怀的能力通过经历/体验得以发展 }\end{array}$ & .730 & .936 & 4.98 & .701 \\
\hline $\begin{array}{l}\text { B30 Spiritual care is important because it gives patient hope } \\
\text { 心灵关怀因给予患者希望而有价值 }\end{array}$ & .718 & .936 & 4.98 & .729 \\
\hline $\begin{array}{l}\text { B31 Spirituality is influenced by individual's life experiences. } \\
\text { 灵性(心灵)受个人生活经历的影响 }\end{array}$ & .740 & .935 & 5.00 & .674 \\
\hline $\begin{array}{l}\text { B32 Spirituality helps when facing life's difficulties and problems. } \\
\text { 灵性(心灵)助力/帮助面对生活的困难和问题 }\end{array}$ & .721 & .936 & 4.94 & .728 \\
\hline $\begin{array}{l}\text { B34 A trusting nurse-patient relationship is needed to provide spiritual care } \\
\text { 提供心灵关怀需基于信任的护患关系 }\end{array}$ & .682 & .937 & 5.13 & .690 \\
\hline $\begin{array}{l}\text { B35 A team approach is important for spiritual care } \\
\text { 团队的方式对心灵关怀很重要 }\end{array}$ & .707 & .936 & 5.04 & .677 \\
\hline $\begin{array}{l}\text { Factor } 2^{\text {b }} \text { Defining Spirituality and Spiritual Care } \\
\text { 维度2:灵性与灵性照护定义(Cronbach's a= 0.852; Guttman Split-Half } \\
\text { coefficient=0.853) }\end{array}$ & & & 4.73 & .89 \\
\hline $\begin{array}{l}\text { B6 Spirituality is about finding meaning in the good and bad events of life } \\
\text { 灵性是指寻找生活中好坏事件的意义 }\end{array}$ & .527 & .843 & 4.57 & 1.064 \\
\hline $\begin{array}{l}\text { B15 Spiritual care is respecting a patient's religious or personal beliefs } \\
\text { 心灵关怀即尊重患者的宗教或个人信仰 }\end{array}$ & .609 & .832 & 4.87 & .941 \\
\hline $\begin{array}{l}\text { B16 Sensitivity and intuition help the nurse to provide spiritual care. } \\
\text { 敏感性和直觉助力护士提供心灵关怀 }\end{array}$ & .588 & .837 & 4.94 & .722 \\
\hline $\begin{array}{l}\text { B17 Being with a patient is a form of spiritual care. } \\
\text { 心灵关怀的形式之一是与患者在一起 }\end{array}$ & 611 & .832 & 4.59 & 1.034 \\
\hline $\begin{array}{l}\text { B18 Nurses provide spiritual care by respecting the religious and cultural beliefs } \\
\text { of patients. } \\
\text { 护士通过尊重患者的宗教和文化信仰为其提供心灵关怀 }\end{array}$ & 649 & .830 & 4.90 & .756 \\
\hline $\begin{array}{l}\text { B19 Nurses provide spiritual care by Giving patients time to discuss and explore } \\
\text { their fears, anxieties and troubles } \\
\text { 护士给予患者足够的时间谈论和探究其恐惧、焦虑和烦恼为其提供心灵关怀 }\end{array}$ & .620 & .832 & 4.90 & .795 \\
\hline $\begin{array}{l}\text { B20 Spiritual care enables the patient to find meaning and purpose in their } \\
\text { illness } \\
\text { 心灵关怀使患者找到其患病的意义和目的 }\end{array}$ & .615 & .831 & 4.61 & 1.053 \\
\hline $\begin{array}{l}\text { B21 Spiritual care includes support to help patients observe their religious } \\
\text { beliefs } \\
\text { 心灵关怀即支持或帮助患者保持其宗教信仰 }\end{array}$ & .593 & .835 & 4.47 & 1.105 \\
\hline Factor $3^{\text {b }}$ Spiritual Perspectives & & & 5.09 & 0.52 \\
\hline
\end{tabular}


Table 4 The results of factor analysis of the 34-item Spiritual Care-Giving Chinese version (C-SCGS) ( $\mathrm{n}=355$ ) (Continued)

\begin{tabular}{|c|c|c|c|c|}
\hline Items & $\begin{array}{l}\text { Corrected item-factor } \\
\text { correlation }\end{array}$ & $\begin{array}{l}\text { Cronbach's a if } \\
\text { item deleted }\end{array}$ & $\begin{array}{l}\text { Average } \\
\text { Mean }\end{array}$ & SD \\
\hline \multicolumn{5}{|l|}{ 维度3:灵性认知 (Cronbach's a = 0.836; Guttman Split-Half coefficient=0.759) } \\
\hline $\begin{array}{l}\text { B1 Everyone has spirituality. } \\
\text { 每个人都有灵性(心灵) }\end{array}$ & .570 & .825 & 5.12 & .785 \\
\hline $\begin{array}{l}\text { B2 Spirituality is an important aspect of human beings. } \\
\text { 灵性是人类的一个重要方面 }\end{array}$ & .673 & .793 & 5.15 & .719 \\
\hline $\begin{array}{l}\text { B3 Spirituality is part of a unifying force which enables individuals to be at } \\
\text { peace } \\
\text { 灵性是能使人平和/安宁、和睦的达成一致的力量部分 }\end{array}$ & .685 & .790 & 5.01 & .740 \\
\hline $\begin{array}{l}\text { B4 Spirituality is an expression of one's inner feelings that affect behaviour. } \\
\text { 灵性是一种影响人的行为的内在情感表达 }\end{array}$ & .672 & .793 & 5.03 & .720 \\
\hline $\begin{array}{l}\text { B5 Spirituality is part of our inner being. } \\
\text { 灵性是我们内心的一部分 }\end{array}$ & .602 & .814 & 5.12 & .622 \\
\hline \multicolumn{5}{|l|}{$\begin{array}{l}\text { Factor } 4^{\mathrm{b}} \text { Spirituality and Spiritual Care Values } \\
\text { 维度4: 灵性与灵性照护价值 (Cronbach's } a=0.866 \text {; Guttman Split-Half } \\
\text { coefficient=0.849) }\end{array}$} \\
\hline $\begin{array}{l}\text { B7 Spiritual well-being is important for one's emotional well-being } \\
\text { 心灵的幸福对个体的情感健康很重要 }\end{array}$ & .622 & .850 & 5.25 & .699 \\
\hline $\begin{array}{l}\text { B8 Spirituality drives individuals to search for answers about meaning and } \\
\text { purpose in life. } \\
\text { 灵性驱使个人寻找生活的意义及其目的的答案 }\end{array}$ & 699 & .842 & 5.01 & .715 \\
\hline $\begin{array}{l}\text { B9 Without spirituality, a person is not considered whole. } \\
\text { 没有灵性, 就不是个完整的人 }\end{array}$ & .534 & .876 & 4.47 & 1.175 \\
\hline $\begin{array}{l}\text { B10 Spiritual needs are met by connecting oneself with other people, higher } \\
\text { power or nature. } \\
\text { 灵性的需求通过自己与他人、更大能量或自然界的联系得到满足 }\end{array}$ & .677 & .843 & 4.87 & .783 \\
\hline $\begin{array}{l}\text { B11 Spiritual care is an integral component of holistic nursing care } \\
\text { 心灵关怀是整体护理的重要组成 }\end{array}$ & .655 & .847 & 5.10 & .679 \\
\hline $\begin{array}{l}\text { B12 Spiritual care is more than religious care. } \\
\text { 心灵关怀不只是宗教的关怀 }\end{array}$ & .681 & .846 & 5.11 & .635 \\
\hline $\begin{array}{l}\text { B13 Nursing care, when performed well, is itself, spiritual care. } \\
\text { 良好的护理本身就是心灵关怀 }\end{array}$ & .628 & .849 & 5.01 & .828 \\
\hline $\begin{array}{l}\text { B14 Spiritual care is a process and not a one- time event or activity. } \\
\text { 心灵关怀是个过程, 而不是一次性事件或活动 }\end{array}$ & .633 & .850 & 5.19 & .646 \\
\hline Cumulative interpretation of variance $\%$ & & & & 53.116 \\
\hline
\end{tabular}

SD Standard deviation

${ }^{\mathrm{b}}$ Spearman-Brown Coefficient $=0.908 ; 0.853 ; 0.811 ; 0.856$; respectively

respectively. Table 4 shows the adjusted item-total correlations, Cronbach's alphas if an item was deleted, means, standard deviations, and cumulative interpretation of variance. The Guttman split-half coefficient of C-SCGS was 0.893 , indicating adequate reliability.

Regarding the concurrent validity of C-SCGS, the correlations of overall C-SCGS and its four factors listed above with the overall SCCS were 0.534, 0.515, 0.490, 0.310 , and 0.439 , respectively $(p<0.01$; see Table 5$)$.

The four-factor model was also chosen to conduct confirmatory factor analysis using another data set from a sample of 351 nurses. The present model provides an acceptable fit to the data $(\mathrm{CMIN} / \mathrm{DF}=2.14$; root mean square error of approximation, RMSEA $=0.06$; goodness-of-fit index, GFI = 0.88; incremental fit index, IFI $=0.92$; adjusted goodness-of-fit index, TLI $=0.91$; comparative fit index, CFI
$=0.92$; An additional figure file shows this in more detail [see Additional file 3].)

Table 6 shows the association between nurses' demographic variables and the four factors of the C-SCGS. We found significant associations with Factor 2, 'Defining Spirituality and Spiritual Care' $(\mathrm{F}=3.540, p=0.015)$, and Factor 4, 'Spirituality and Spiritual Care Values' ( $\mathrm{F}=3.069, p$ $=0.028)$. The nurses with secondary vocational schooling and undergraduate-level education appeared to score higher in perceptions of spirituality and spiritual care. The post hoc analysis (also see Fig. 2. Means Plots of SCGS_factor 2 and factor 4) showed a significantly higher proportion of undergraduate nurses who possessed more positive perspectives on 'Defining Spirituality and Spiritual Care' and 'Spirituality and Spiritual Care Values' than nurses with graduate-level education and above (mean 
Table 5 Cronbach's alpha and Pearson's Product-Moment Correlation between the Two Scales (SCGS \& C-SCCS)

\begin{tabular}{|c|c|c|c|c|c|c|c|c|c|}
\hline Measures & C-SCGS & Factor 1 & Factor 2 & Factor 3 & Factor4 & C-SCCS & C-SCCS 1 & C-SCCS 2 & C-sCCS 3 \\
\hline \multicolumn{10}{|l|}{ C-SCGS } \\
\hline Factor 1 & $0.924^{* *}$ & $a=0.941$ & & & & & & & \\
\hline Factor 2 & $0.829^{* *}$ & $0.661^{* *}$ & $a=0.852$ & & & & & & \\
\hline Factor 3 & $0.741^{* *}$ & $0.618^{* *}$ & $0.451^{* *}$ & $a=0.836$ & & & & & \\
\hline Factor4 & $0.891^{* *}$ & $0.763^{* *}$ & $0.634^{* *}$ & $0.675^{* *}$ & $a=0.866$ & & & & \\
\hline C-SCCS & $0.534^{* *}$ & $0.515^{* *}$ & $0.490^{* *}$ & $0.310^{* *}$ & $0.439^{* *}$ & & & & \\
\hline C-sCCS 1 & $0.519^{* *}$ & $0.497^{* *}$ & $0.464^{* *}$ & $0.307^{* *}$ & $0.441^{* *}$ & $0.441^{* *}$ & $a=0.934$ & & \\
\hline C-sccs 2 & $0.342^{* *}$ & $0.309^{* *}$ & $0.404^{* *}$ & $0.134^{*}$ & $0.248^{* *}$ & $0.248^{* *}$ & $0.731^{* *}$ & $a=0.917$ & \\
\hline C-sccs 3 & $0.526^{* *}$ & $0.550^{* *}$ & $0.359^{* *}$ & $0.402^{* *}$ & $0.452^{* *}$ & $0.452^{* *}$ & $0.510^{* *}$ & $0.392^{* *}$ & $a=0.855$ \\
\hline
\end{tabular}

Pearson's correlation coefficient test was used, two-tailed. Cronbach's alpha on the diagonal in parenthesis. Spiritual Care-Giving Rating Scale (C-SCGS): Attributes for Spiritual Care (Factor 1), Defining Spirituality and Spiritual Care (Factor 2), Spirituality Perspectives (Factor 3), Sprituality and Spiritual Care Values (Factor 4). Spiritual Care Competency Scale (C-SCCS): Assessment, implementation, professionalization and quality improvement of spiritual care (C-SCCS 1), Personal and team support (C-SCCS 2), Attitude towards patient spirituality and communication (C-SCCS 3)

${ }^{*} p<0.05 ; * * 0.01$

difference (I-J), 3.08; std. error, $1.01 ; p=0.03$ for undergraduate nurses; mean difference (I-J): 2.03 ; std. error: $0.87 ; \mathrm{p}=0.02$ for graduate nurses). Neither gender, age nor income were associated with nurses' perceptions of spirituality and spiritual care.

\section{Discussion}

It is important to find a valid and reliable measurement to identify nurses' current perspectives on spiritual care and spirituality to inform the education and training sector, especially in China. The main aim of this study was to translate the SCGS into Chinese and examine its reliability and validity. The participants of this study were recruited from eight different types and levels of hospitals and various departments. Therefore, the results represented nurses with diverse backgrounds.

The main finding of this article is that, after excluding one item of the current SCGS from the homogeneity and factorial analyses, this tool is useful to identify nurses' perspectives on spirituality and spiritual care in nursing practice. Thus, in the final version of the C-SCGS, high scores are strongly correlated with spiritual care-giving level. Additionally, spiritual care perception levels were associated with education in this cohort of nurses.

Compared with the original English version of the SCGS, the C-SCGS performed well in four dimensions. An EFA determined 34 items categorized under four factors, which explained $53.116 \%$ of the total variance of every dimension. All items had a factor loading of 0.60 or higher, which was considered ideal. However, these results had minor differences from those reported in studies conducted by Tiew et al. [21], who performed an EFA with the whole scale including 35 items and obtained five common factors. We conducted a factor analysis for our samples using the same method (principal component analysis, PCA), but we found that the content of the items contained in the factors was quite different from the original theoretical structure. Similar to the results of the original SCGS with five factors with $r$ $=0.581-0.765$, all factors in the present scale were also significantly and moderately correlated $(r=0.399$ to $r=$ $0.741 ; p<0.01)$ with each other. Thus, we used the principal axis factoring extraction method using the Promax with Kaiser normalization rotation method and found that the fifth factor contained only one item. After item 33 was deleted, the factor analysis was rerun, and a four-factor model was obtained.

The 34-item C-SCGS demonstrated acceptable concurrent validity. A statistically significant correlation (both scales measured similar subjects regarding spirituality and spiritual care, although one assesses perceptions of spirituality and spiritual care and the other evaluates the level of competence of spiritual care) was found between C-SCGS and C-SCCS $(r=0.534, P<0.01$; generally, 0.4 to 0.7 is considered to be moderately correlated), which revealed that the C-SCGS performed with acceptable concurrent validity when assessed against the C-SCCS. Therefore, to some extent, this scale was sensitive enough to evaluate similar features to those described by the C-SCCS.

The Cronbach's alpha of the four factors, with values of $0.941,0.852,0.836$, and 0.866 , showed good internal consistency; the correlation of 0.893 of the split-half internal consistency test also suggested the sound reliability of C-SCGS. The results of this study were consistent with the results for the original English version, in which Cronbach's alpha ranged from 0.811 to 0.90 [21]. The results were also consistent with a later test in nurses in Singapore in which a Cronbach's alpha coefficient of 0.97 was obtained [22].

Concerning the translation of the C-SCGS, most items had culturally equivalent terms in Chinese. Therefore, 
Table 6 Association between the Chinese version of the Spiritual Care-Giving Scale and personal issues

\begin{tabular}{|c|c|c|c|c|c|c|c|}
\hline Test Variable & Groups & $\begin{array}{l}\text { Frequency } \\
\text { (n) }\end{array}$ & $\begin{array}{l}\text { Total } \\
(\mathrm{M} \pm \mathrm{SD})\end{array}$ & $\begin{array}{l}\text { Factor } 1 \text { (M } \\
\pm \text { SD) }\end{array}$ & $\begin{array}{l}\text { Factor2 (M } \\
\pm \text { SD) }\end{array}$ & $\begin{array}{l}\text { Factor } 3(\mathrm{M} \\
\pm \mathrm{SD})\end{array}$ & $\begin{array}{l}\text { Factor } 4 \text { (M } \\
\pm \text { SD) }\end{array}$ \\
\hline \multirow[t]{2}{*}{ Gender } & Male & 17 & $\begin{array}{l}162.29 \\
\pm 19.83\end{array}$ & $63.41 \pm 7.27$ & $36.41 \pm 6.10$ & $24.29 \pm 3.18$ & $38.18 \pm 6.26$ \\
\hline & Female & 338 & $\begin{array}{l}168.79 \\
\pm 16.76\end{array}$ & $65.27 \pm 6.97$ & $37.93 \pm 5.25$ & $25.49 \pm 2.77$ & $40.11 \pm 4.41$ \\
\hline t value & & & -1.545 & -1.071 & -1.153 & -1.719 & -1.256 \\
\hline$P$ value & & & .123 & .285 & .250 & .087 & .226 \\
\hline \multirow[t]{5}{*}{ Age, years } & $\geq 18$ & 54 & $\begin{array}{l}168.70 \\
\pm 16.48\end{array}$ & $65.41 \pm 6.59$ & $38.22 \pm 4.96$ & $25.43 \pm 2.66$ & $39.65 \pm 4.46$ \\
\hline & $\geq 26$ & 130 & $\begin{array}{l}167.53 \\
\pm 16.31\end{array}$ & $64.83 \pm 6.97$ & $37.72 \pm 5.01$ & $25.24 \pm 2.79$ & $39.74 \pm 4.69$ \\
\hline & $\geq 31$ & 129 & $\begin{array}{l}168.75 \\
\pm 17.24\end{array}$ & $65.28 \pm 7.15$ & $37.90 \pm 5.48$ & $25.40 \pm 2.85$ & $40.17 \pm 4.31$ \\
\hline & $\geq 41$ & 36 & $\begin{array}{l}170.61 \\
\pm 18.25\end{array}$ & $65.86 \pm 6.83$ & $37.56 \pm 6.21$ & $26.31 \pm 2.69$ & $40.89 \pm 4.76$ \\
\hline & $\geq 51$ & 6 & $\begin{array}{l}168.33 \\
\pm 24.22\end{array}$ & $64.50 \pm 9.65$ & $38.33 \pm 6.02$ & $24.83 \pm 3.49$ & $40.67 \pm 5.47$ \\
\hline$F$ value & & & .253 & .200 & .127 & 1.108 & .612 \\
\hline$P$ value & & & .908 & .938 & .973 & .353 & .654 \\
\hline \multirow[t]{4}{*}{ Education } & $\begin{array}{l}\text { Secondary vocational schools } \\
\text { (A) }\end{array}$ & 3 & $\begin{array}{l}182.33 \\
\pm 34.96\end{array}$ & $70.00 \pm 13.86$ & $41.33 \pm 9.87$ & $27.33 \pm 4.62$ & $43.67 \pm 6.66$ \\
\hline & Junior college (B) & 72 & $\begin{array}{l}167.36 \\
\pm 16.23\end{array}$ & $65.17 \pm 6.45$ & $37.74 \pm 4.87$ & $25.11 \pm 2.53$ & $39.36 \pm 4.67$ \\
\hline & Undergraduate (C) & 250 & $\begin{array}{l}169.18 \\
\pm 16.80\end{array}$ & $65.13 \pm 6.96$ & $38.18 \pm 5.31$ & $25.50 \pm 2.78$ & $40.36 \pm 4.28$ \\
\hline & Postgraduate or above (D) & 30 & $\begin{array}{l}163.93 \\
\pm 17.46\end{array}$ & $65.13 \pm 7.82$ & $35.10 \pm 5.02$ & $25.37 \pm 3.35$ & $38.33 \pm 4.54$ \\
\hline$F$ vaue & & & 1.640 & .479 & 3.540 & .838 & 3.069 \\
\hline$P$ value & & & .180 & .697 & $.015^{*}$ & .474 & $.028^{*}$ \\
\hline \multirow[t]{3}{*}{ Post Hoc Tests } & Scheffe's method & & & & $C>D^{a}$ & & \\
\hline & Tukey HSD & & & & $C>D^{b}$ & & \\
\hline & LSD method & & & & $\mathrm{B}>\mathrm{C}^{\mathrm{c}} ; \mathrm{C}>\mathrm{D}^{\mathrm{d}}$; & & $C>D^{e}$ \\
\hline \multirow[t]{2}{*}{$\begin{array}{l}\text { Income( } ¥ / \\
\text { month) }\end{array}$} & $<5000$ & 193 & $\begin{array}{l}169.31 \\
\pm 17.44\end{array}$ & $65.46 \pm 7.14$ & $38.33 \pm 5.32$ & $25.33 \pm 2.80$ & $40.19 \pm 4.45$ \\
\hline & $\geq 5000$ & 162 & $\begin{array}{l}167.49 \\
\pm 16.34\end{array}$ & $64.85 \pm 6.80$ & $37.29 \pm 5.22$ & $25.55 \pm 2.79$ & $39.81 \pm 4.62$ \\
\hline $\mathrm{t}$ value & & & 1.003 & .827 & .827 & -.748 & .783 \\
\hline$P$ value & & & .316 & .409 & .065 & .455 & .434 \\
\hline
\end{tabular}

* $\mathrm{p}<0.05$; LSD Least significant difference, HSD Honestly significant difference

a Mean Difference (I-J), 3.08*; Std. Error, 1.01; P=.03

${ }^{b}$ Mean Difference (I-J): 3.08*; Std. Error: 1.01; $P=.01$

c Mean Difference (I-J): 2.64*; Std. Error: 1.14; $P=.02$

${ }^{\mathrm{d}}$ Mean Difference (I-J): 3.08*; Std. Error: 1.01; $P=.00$

${ }^{e}$ Mean Difference (I-J): 2.03*; Std. Error: .87; P=.02

we were able to translate the questionnaire without extensive adaptation. There were two exceptions. One was the concept of "spiritual." Dr. Leeuwen was consulted on the translation and modification of some of the expressions. The other exception was that, to adapt to the cultural background, we used the Chinese word “心灵” as an equivalent to the word “灵性” (spirituality) in some sentence expressions because some experts and clinical nurses suggested that the direct translation of the word spirituality is not easy to understand. We consulted Dr. Tiew, the developer of SCGS, who is familiar with both English and Chinese, and obtained her approval about this adaptation. It should also be noted that some experts suggest deleting religion-related content from the C-SCGS because most nurses in China are nonreligious. However, given that the research team found a certain 

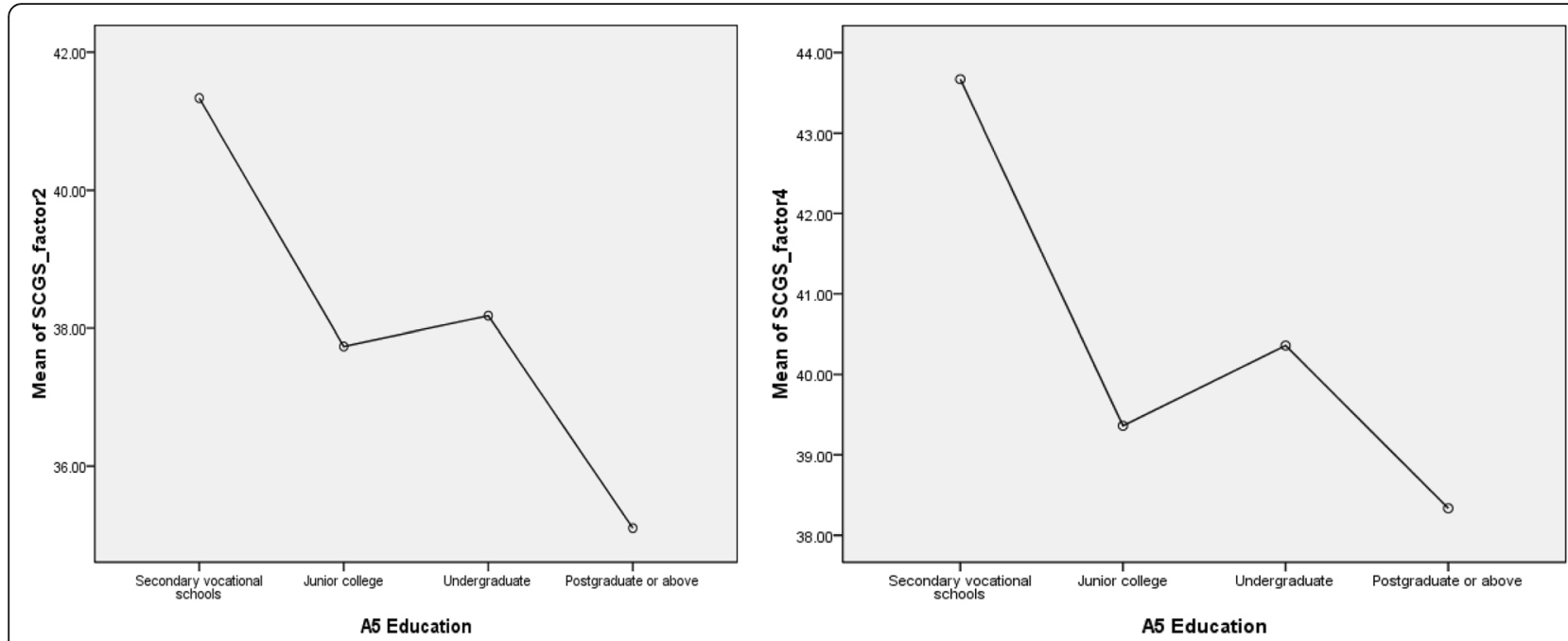

Fig. 2 Means Plots of SCGS_factor 2 and factor 4

relationship between religion and spiritual cognition when they read the literature, and indeed some Chinese nurses believe in Christianity and Buddhism, the scale retained the items related to religion.

The number of items to be retained at each subscale was determined, and the factors were given similar labels to those provided by the original author: attributes of spiritual care (Factor 1); definitions of spirituality and spiritual care (Factor 2); spirituality perspectives (Factor 3 ); and spirituality and spiritual care values (Factor 4). The Chinese version of the Spiritual Care-Giving Scale can be seen in the supplementary table in Additional file 4.

This study has several shortcomings. First, the sample of nurses was mainly from the Henan and Jilin provinces of China and was obtained using a convenience sampling method; therefore, the findings may not represent the opinions of all nurses in China. Second, there is the possibility of a social desirability bias in the responses. The nurses may have chosen responses that were consistent with their leaders' expectations even though their participation was voluntary and their anonymity ensured. This possibility is due to the special cultural and systemic background. In most departments in most hospitals in China, leaders have authority over employee bonuses and work arrangements. Additionally, leaders always hope for their organizations to have a positive image. As a result, employees may subconsciously conform to the expectations of their leaders. Third, the use of the online-based questionnaire format instead of the original paper-based SCGS could lead to differences in validity between the online and paper forms. The use of an online questionnaire could also influence on the responses due to unfamiliarity with online questionnaires and potential errors in answering using a mobile device.
The results have certain implications for future research. The C-SCCS was used to evaluate the concurrent validity of the C-SCGS because the C-SCCS measures the spiritual care competency of student nurses. There was a moderately strong relationship between the C-SCGS and C-SCCS. Future studies may attempt to establish a structural equation model (SEM) to further analyze the factors influencing nurses' spiritual care perceptions and abilities and their relationships. The findings of the current study provide further support for the validity and reliability of the SCGS for the measurement of nurses' awareness, knowledges, attitudes, and perspectives on spiritual care and spirituality. However, the C-SCGS CFA test supported the results of the fitting model after modification (see Fig. 2 ). This observation may be partly explained by the relatively small sample size, as large samples always show better RMSEA [31]. It may also means that the model has multiple collinearity due to cross loading and needs further modification. Future research should enlarge the sample size and try to use exploratory structural equation modeling (ESEM), which integrates features of CFA, EFA) and SEM in a single framework to overcome certain limits of CFA [32, 33].

This study has implications for clinical nursing. First, given the evidence for the advantages of recognizing nurses' perspectives of spirituality and spiritual care, in recent years, studies assessing this subject have increased [18, 34-36]. Although some of them show that spiritual care can improve patients' and all people's health outcomes, the topic is not given adequate attention in nursing practice. One of the main barriers may be limitations of nurses' understanding of spirituality and spiritual care, which is essential for best practice. To provide spiritual care, nurses need to be knowledgeable regarding the topics of spirituality and spiritual care and their own 
perceptions and attitudes towards this issue. Identifying these issues using a valid instrument proven by the current study will allow nurses to explore available resources to assist in improving their knowledge and ability to provide spiritual care and meet patients' spiritual needs. Second, although the SCGS was first developed as an instrument to assess student nurses' spirituality and spiritual care perspectives, it was found to be a valid and reliable multidimensional tool for use in Chinese clinical nursing staff with a multicultural background. Findings from the C-SCGS would assist clinical nursing managers in evaluating staff members' understanding of spirituality and spiritual care and their perspectives on these topics. Identifying problems in these areas will allow managers to formulate strategies to empower nurses through education, provide them with spiritual care skills for optimal practice, and assist them in improving care quality.

Importantly, our results also revealed that nurses with lower levels of education (junior college and undergraduate) scored higher on the C-SCGS. Additionally, undergraduate nurses reported, statistically significantly higher level perceptions of spirituality and spiritual care than nurses with graduate-level education or above. This difference may be because of the small sample of nurses with graduate and above education. However, there might be other reasons which should be explored with greater attention.

\section{Conclusions}

The results of this study showed that the 34-item C-SCGS has satisfactory concurrent validity, construct validity, and internal consistency. It was found to be a potentially helpful instrument to measure mainland Chinese nurses' perceptions regarding spirituality and spiritual care. Education was significantly associated with the scores in the C-SCGS and therefore with different perceptions of spirituality and spiritual care levels. The details of this association and its reasons need to be analyzed further. Future research should try to use ESEM to overcome some of the limits of CFA and to further verify the validation of the C-SCGS used in this study, recruit a larger sample that is more representative of the Chinese nursing population, translate the C-SCGS into other native dialects, or apply it in other settings such as palliative care.

\section{Additional files}

Additional file 1: Table S1. Internal consistency of 35-items C-SCGS ( $n$ =355). (DOCX $20 \mathrm{~kb})$

Additional file 2: Table S2. The Structure Matrix of the 35-items CSCGS. (DOCX $24 \mathrm{~kb})$
Additional file 3: Figure S1. Results of the confirmatory factor analysis. (DOCX 253 kb)

Additional file 4: The Chinese version of the Spiritual Care-Giving Scale. (DOCX $20 \mathrm{~kb}$ )

\section{Abbreviations \\ CFA: Confirmatory factor analysis; CR: The criterial value; C-SCCS: The Chinese version of the Spiritual Care Competency Scale; C-SCGS: The Chinese version of the Spiritual Care-Giving Scale; CVI: The content validity of item; EFA: Exploratory factor analysis; ESEM: Exploratory structural equation modeling; KMO: Kaiser-Meyer-Olkin; SCGS: The Spiritual Care-Giving Scale; SEM: Structural Equation Model; SSCRS: The Spirituality and Spiritual Care Rating Scale; TVI: The Translation Validity Index}

\section{Acknowledgements}

The authors are grateful to Yingying Li and Wanhong Wei, who contacted with the author of the SCGS to obtain the translation permission of it, reviewed the translated version of the SCGS, and assisted in the data collection. We thank Feng Li, Gaojie Yue, Ying Chen, Cancan Chen, and Jianmei Gong for their assistances on verification and modification of the translated version of the C-SCGS. We also thank Xiaohui Liu, Cancan Chen, and Caihua Tian for their assistances on data collection.

\section{Funding}

This work was supported by grants from the National Natural Science Foundation of China (\#81320108025 and \#81672109) and the Graduate Innovation Fund of Jilin University (101832018C088). The funding did not have any role in the design of the study and collection, analysis, and interpretation of data and in writing the manuscript.

\section{Availability of data and materials}

The datasets generated and/or analyzed during the current study are available upon the request from the coauthor Yanli Hu, in the format of SPSS files.

\section{Authors' contributions}

YLH led the analysis plan, conducted the data analysis, interpretation of findings and drafted the manuscript. LHT confirmed and modified the backtranslated version of the SCGS, reviewed the manuscript, revised it critically for important intellectual content, and edited it to make it read well in English. FL was responsible for the study design, supervised the study, led the data collection, contacted experts to translate and revise the manuscript, and approval of the final draft.

\section{Ethics approval and consent to participate}

Informed written consent was obtained from all participants. The present study has been reviewed and approved by the Institute Review Board of College of Nursing, Jilin University (access number: 2018031102).

\section{Consent for publication}

Not applicable.

\section{Competing interests}

The authors declare that they have no competing interests.

\section{Publisher's Note}

Springer Nature remains neutral with regard to jurisdictional claims in published maps and institutional affiliations.

\section{Author details}

${ }^{1}$ School of Nursing, Jilin University, Changchun, China. ${ }^{2}$ National University Hospital, Alice Lee Centre for Nursing Studies, National University of Singapore, Singapore, Singapore. ${ }^{3}$ Department of Pathogenobiology, The Key Laboratory of Zoonosis research, Chinese Ministry of Education, College of Basic Medicine, Jilin University, No.126 Xinmin Street, Changchun, China. ${ }^{4}$ The Key Laboratory for Bionics Engineering, Ministry of Education, Jilin University, Changchun, China. ${ }^{5}$ State Key Laboratory of Pathogenesis, Prevention and Treatment of High Incidence Diseases in Central Asia, Urumqi, China. 
Received: 22 October 2018 Accepted: 9 January 2019

Published online: 23 January 2019

\section{References}

1. Zimmermann C, Swami N, Krzyzanowska M, Hannon B, Leighl N, Oza A, et al. Early palliative care for patients with advanced cancer: a clusterrandomized controlled trial. Lancet. 2014:383(9930):1721-30.

2. Addressin COAD. Dying in America: improving quality and honoring individual preferences near the end of life. Mil Med. 2015;180(4):365-7.

3. Van $L R$, Tiesinga $L J$, Post $D$, Jochemsen $H$. Spiritual care: implications for nurses' professional responsibility. J Clin Nurs. 2006;15(7):875.

4. Sidebottom AC, Jorgenson A, Richards H, Kirven J, Sillah A. Inpatient palliative care for patients with acute heart failure: outcomes from a randomized trial. J Palliat Med. 2015;18(2):134-42.

5. Wong FKY, Ng AYM, Lee PH, Lam P, Ng JSC, Ng NHY, et al. Original article: effects of a transitional palliative care model on patients with end-stage heart failure: a randomised controlled trial. Heart. 2016;102(14):1100-8.

6. Grudzen CR, Richardson LD, Johnson PN, Hu M, Wang B, Ortiz JM, et al. Emergency department-initiated palliative Care in Advanced Cancer: a randomized clinical trial. Jama Oncology. 2016;2(5):591-8.

7. Kavalieratos D, Corbelli J, Zhang D, Dionne-Odom JN, Ernecoff NC, Hanmer J, et al. Association between palliative care and patient and caregiver outcomes: a systematic review and meta-analysis. JAMA. 2016;316(20):2104

8. Lazenby M, Khatib J, Al-Khair F, Neamat M. Psychometric properties of the functional assessment of chronic illness therapy—spiritual well-being (FACIT-Sp) in an Arabic-speaking, predominantly Muslim population. Psycho-Oncology. 2013;22(1):220-7.

9. Zimmermann C, Swami N, Krzyzanowska M, Leighl N, Rydall A, Rodin G, et al. Perceptions of palliative care among patients with advanced cancer and their caregivers. CMAJ. 2016;188(10):E217-27.

10. Zimmermann C, Riechelmann R, Krzyzanowska M, Rodin G, Tannock I. Effectiveness of specialized palliative care: a systematic review. JAMA. 2008; 299(14):1698-709.

11. Allahbakhshian M, Jaffarpour M, Parvizy S, Haghani HA. Survey on relationship between spiritual wellbeing and quality of life in multiple sclerosis patients. Zahedan J Res Med Sci. 2010;12(3):670-5.

12. Ross L, Van LR, Baldacchino D, Giske T, Mcsherry W, Narayanasamy A, et al. Student nurses perceptions of spirituality and competence in delivering spiritual care: a European pilot study. Nurse Educ Today. 2014;34(5):697.

13. Van Leeuwen $R$, Tiesinga $L$, Middel B, Post $D$, Jochemsen $H$. The effectiveness of an educational programme for nursing students on developing competence in the provision of spiritual care. J Clin Nurs. 2008; 17(20):2768-81.

14. Baldacchino DR. Teaching on spiritual care: the perceived impact on qualified nurses. Nurse Educ Pract. 2011;11(1):47-53.

15. Paal P, Helo Y, Frick E. Spiritual care training provided to healthcare professionals: a systematic review. J Pastoral Care Counsel Jpcc. 2015;69(1):19.

16. Gallison BS, Xu Y, Jurgens $C Y$, Boyle SM. Acute care nurses' spiritual care practices. J Holist Nurs Official Journal of the American Holistic Nurses Association. 2013;31(2):95.

17. Nazari R, Fatemi M, Safavi M. Nurse's spirituality, spiritual care, patient satisfaction. Tabriz University of medical; 2011.

18. Mcsherry W, Jamieson S. An online survey of nurses' perceptions of spirituality and spiritual care. J Clin Nurs. 2011;20(11-12):1757.

19. Petersen $\mathrm{CL}$, Callahan MF, Mccarthy DO, Hughes RG, White-Traut R, Bansal NK. An online educational program improves pediatric oncology Nurses' knowledge, attitudes, and spiritual care competence. J Pediatr Oncol Nurs official Journal of the Association of Pediatric Oncology Nurses. 2016;34(2):130.

20. Mcsherry W, Draper $P$, Kendrick D. The construct validity of a rating scale designed to assess spirituality and spiritual care. Int J Nurs Stud. 2002;39(7):723-34.

21. Tiew LH, Creedy DK. Development and preliminary validation of a composite spiritual care-giving scale. Int J Nurs Stud. 2012;49(6):682-90.

22. Chew BW, Tiew LH, Creedy DK. Acute care nurses' perceptions of spirituality and spiritual care: an exploratory study in Singapore. J Clin Nurs. 2016; 25(17-18):2520-7.

23. Muthén LK, Muthén BO. How to use a Monte Carlo study to decide on sample size and determine power[J]. Struct Equ Model Multidiscip J. 2002; 9(4):599-620.

24. Leeuwen RR, Tiesinga $L$, Middel $L$, Jochemsen H, Post D. An instrument to measure nursing competencies in spiritual care: validity and reliability of Spiritual Care Competence Scale (SCCS), vol. 6; 2009. p. 132-51.
25. Brislin RW. The wording and translation of research instruments, vol. 8; 1986 p. 137-64.

26. Tang ST, Dixon J. Instrument translation and evaluation of equivalence and psychometric properties: the Chinese sense of coherence scale. J Nurs Meas. 2002;10(1):59.

27. Polit-O'Hara D, Hungler BP. Study guide to accompany nursing research: principles and methods; 1999.

28. SO JUMP. Available from: https://www.wjx.cn/?source=baidu\&plan= \%E9\%97\%AE\%E5\%8D\%B7\%E6\%98\%9F\&keyword= \%E9\%97\%AE\%E5\%8D\%B7\%E6\%98\%9FBH.

29. Ortqvist M, Iversen MD, Janarv PM, Broström EW, Roos EM. Psychometric properties of the knee injury and osteoarthritis outcome score for children (KOOS-child) in children with knee disorders. Br J Sports Med. 2014;48(19): 1437-46.

30. Norman GR, Streiner DL. PDQ statistics; 2003.

31. Vaingankar JA, Subramaniam M, Tan LWL, et al. Psychometric properties and population norms of the positive mental health instrument in a representative multi-ethnic Asian population [J]. BMC Med Res Methodol. 2018;18(1):29.

32. Asparouhov T, Muthén B. Exploratory structural equation modeling. Struct Equ Model Multidiscip J. 2009;16(3):397-438.

33. Marsh HW, Morin AJS, Parker PD, Kaur G. Exploratory structural equation modeling: an integration of the best features of exploratory and confirmatory factor analysis. Annu Rev Clin Psychol. 2014;10(10):85-110.

34. Tiew LH, Drury V, Creedy D. Singapore nursing students' perceptions about spirituality and spiritual care: a qualitative study. Support Palliat Care. 2011; $1(1): 84$

35. Daghan S. Nursing Students' perceptions of spirituality and spiritual care: an example of Turkey. J Relig Health. 2018;57(1):1-11.

36. Folami F, Onanuga KA. Perception of spirituality, spiritual care, and barriers to the provision of spiritual care among undergraduate nurses in the University of Lagos, Nigeria. 2018; 15 (1):8.

Ready to submit your research? Choose BMC and benefit from

- fast, convenient online submission

- thorough peer review by experienced researchers in your field

- rapid publication on acceptance

- support for research data, including large and complex data types

- gold Open Access which fosters wider collaboration and increased citations

- maximum visibility for your research: over $100 \mathrm{M}$ website views per year

At $\mathrm{BMC}$, research is always in progress.

Learn more biomedcentral.com/submissions 